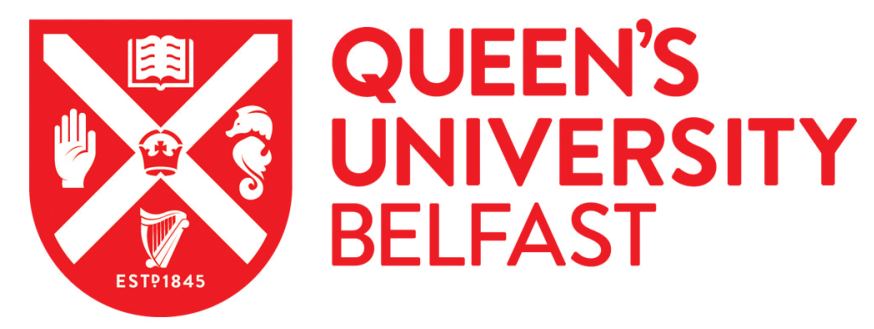

\title{
Generational difference of refractive error and risk factors in the Handan offspring myopia study
}

Lin, Z., Gao, T. Y., Vasudevan, B., Jhanji, V., Ciuffreda, K. J., Zhang, P., Li, L., Mao, G. Y., Wang, N. L., \& Liang, Y. B. (2014). Generational difference of refractive error and risk factors in the Handan offspring myopia study. Investigative Ophthalmology and Visual Science, 55(9), 5711-5717. https://doi.org/10.1167/iovs.13-13693

\section{Published in:}

Investigative Ophthalmology and Visual Science

Document Version:

Publisher's PDF, also known as Version of record

\section{Queen's University Belfast - Research Portal:}

Link to publication record in Queen's University Belfast Research Portal

\section{Publisher rights}

Copyright 2014, The Association for Research in Vision and Ophthalmology, Inc.

This work is made available online in accordance with the publisher's policies. Please refer to any applicable terms of use of the publisher.

\section{General rights}

Copyright for the publications made accessible via the Queen's University Belfast Research Portal is retained by the author(s) and / or other copyright owners and it is a condition of accessing these publications that users recognise and abide by the legal requirements associated with these rights.

Take down policy

The Research Portal is Queen's institutional repository that provides access to Queen's research output. Every effort has been made to ensure that content in the Research Portal does not infringe any person's rights, or applicable UK laws. If you discover content in the Research Portal that you believe breaches copyright or violates any law, please contact openaccess@qub.ac.uk. 


\title{
Generational Difference of Refractive Error and Risk Factors in the Handan Offspring Myopia Study
}

\author{
Zhong Lin,,${ }^{1,2}$ Tie Ying Gao, ${ }^{3}$ Balamurali Vasudevan, ${ }^{4}$ Vishal Jhanji, ${ }^{5}$ Kenneth J. Ciuffreda,${ }^{6}$ \\ Peng Zhang, ${ }^{3}$ Lei Li, ${ }^{3}$ Guang Yun Mao, ${ }^{1,7,8}$ Ning Li Wang, ${ }^{2}$ and Yuan Bo Liang ${ }^{1,2}$
}

\author{
${ }^{1}$ The Affiliated Eye Hospital, School of Optometry and Ophthalmology, Wenzhou Medical University, Wenzhou, Zhejiang, China \\ ${ }^{2}$ Beijing Tongren Eye Center, Beijing Tongren Hospital, Capital Medical University, Beijing Ophthalmology and Visual Science Key \\ Lab, Beijing, China \\ ${ }^{3}$ Handan Eye Hospital, Handan, Hebei, China \\ ${ }^{4}$ College of Optometry, Midwestern University, Glendale, Arizona, United States \\ ${ }^{5}$ Department of Ophthalmology and Visual Sciences, The Chinese University of Hong Kong, Hong Kong, China \\ ${ }^{6}$ Department of Biological and Vision Sciences, State University of New York College of Optometry, New York, New York, United \\ States \\ ${ }^{7}$ School of Environmental Science and Public Health, Wenzhou Medical University, Wenzhou, Zhejiang, China \\ ${ }^{8}$ Johns Hopkins Bloomberg School of Public Health, Baltimore, Maryland, United States
}

Correspondence: Yuan Bo Liang, The Affiliated Eye Hospital, School of Optometry and Ophthalmology, Wenzhou Medical University, No. 270 West College Road, Wenzhou, Zhejiang, China 325027; yuanboliang@126.com.

ZL and TYG contributed equally to the work presented here and should therefore be regarded as equivalent authors.

Submitted: November 29, 2013

Accepted: June 26, 2014

Citation: Lin Z, Gao TY, Vasudevan B, et al. Generational difference of refractive error and risk factors in the Handan Offspring Myopia Study. Invest Ophthalmol Vis Sci. 2014;55:5711-5717. DOI:10.1167/ iovs.13-13693
Punpose. To report the refractive error difference (RED) between parents and their children, and its risk factors, in a rural area of China.

Methods. Children (6-17 years) and their parents (36.2 \pm 4.1 years) from the Handan Offspring Myopia Study (HOMS) were enrolled. Cycloplegic autorefraction (cyclopentolate $1 \%$, Topcon KR8800) of the children and noncycloplegic autorefraction of their parents were assessed. A detailed vision-based questionnaire was also completed. Refractive error difference was defined as the difference between the parental spherical equivalent (SE) and their children's SE. Generational myopic shift was defined as the estimated RED when a child would be 18 years old according to a prediction model.

REsults. Three hundred fifty-six pairs of parents and 585 children were enrolled. The RED (median, quartiles) increased from $-1.33(-1.99,-0.98)$ diopters (D) in children aged 6 to 7 years to $0.81(-0.16,2.28) \mathrm{D}$ in children aged 16 to 17 years. The children's SE was predicted to approach the parental SE at 14 years of age. Moreover, the children's estimated myopic shift would be $1.03 \mathrm{D}$. Multiple linear regression revealed that older children $(\beta=0.23 \mathrm{D} / \mathrm{y}$, $P<0.0001)$ and girls $(\beta=0.24, P=0.01)$ tended to have a higher RED.

Conclusions. In this rural Chinese population, the children's refraction was estimated to be similar to the parental refraction at 14 years of age. Moreover, the generational myopic shift was estimated to be approximately $1 \mathrm{D}$ at 18 years of age. These data suggest that the generational difference reflects the increasing prevalence of myopia in the younger generation, which is likely due to changes in environmental exposure.

Keywords: refractive error, myopia, risk factors
$\mathbf{M}$ yopia is the most common visual disorder affecting children in both the rural and urban populations in East Asia. ${ }^{1-6}$ Epidemiological studies have found a remarkable increase in the prevalence of myopia in children in this area. ${ }^{7-9}$ Lin et al. ${ }^{8}$ found that the prevalence of myopia in 12-year-old children increased from $36.7 \%$ in 1983 to $61.0 \%$ in 2000 . In China, the prevalence of myopia in the Chinese adult ( 40 years or older) population in urban (Beijing) and rural (Handan) areas is similar (approximately 20\%). ${ }^{10,11}$ However, the prevalence of myopia and the average refractive error in 15-year-old children in urban China (Guangzhou) are $78.4 \%$ and -1.50 diopters (D), respectively, ${ }^{2}$ which is significantly greater than in children of the same age residing in rural China (e.g., Yangxi, a rural area located west of Guangzhou) ( $43.0 \%$ and $-0.50 \mathrm{D}$, respectively). ${ }^{3}$ These data suggest that differences in lifestyle and exposure to environmental factors between parents and their children, as well as between the rural and urban younger generation in China, may be important factors. ${ }^{12-16}$

Our recent report from the Beijing Myopia Progression Study (BMPS) demonstrated that the predicted age when a child's spherical equivalent (SE) was similar to the average SE of his or her parents was 11 years, and furthermore that the generational myopic shift from parents to their children was $1.94 \mathrm{D}$ in urban Beijing. ${ }^{16}$ Estimation of the myopic shift between these two generations appears to reflect environmental effects, such as more intensive near work, longer educational duration, and less outdoor activity, 8,9 on the development of myopia in this relatively short span of time. There may also be a difference in the effect of environmental factors on the development of myopia between the urban and rural younger generation. ${ }^{3,13,17}$ Hence, given the relatively close genetic backgrounds among people living in the urban and rural areas in the same region, it is useful to compare the generational myopic shift between the two areas. 
The Handan Offspring Myopia Study (HOMS) was designed to determine the prevalence of myopia among rural children, namely, the offspring of the Handan Eye Study (HES) population, ${ }^{18}$ especially with respect to family history. ${ }^{19}$ The HOMS also investigated the correlation between childhood and parental myopia. ${ }^{19}$ It is noteworthy that children from the HOMS were in the same age range as those in the BMPS and received vision examinations (e.g., visual acuity, ocular biometry, cycloplegic autorefraction) and questionnaires similar to those in the BMPS. ${ }^{19,20}$

The aim of this study was to determine the age-specific refractive error difference (RED) between parents and their children and the risk factors for RED in the HOMS, and furthermore to compare the generational myopic shift between the rural and urban areas of China.

\section{MeTHODS}

\section{Subjects}

Details, rationale, design, and methodology of the HOMS were reported elsewhere. ${ }^{19}$ Briefly, in 2006 to 2007 , a populationbased eye study in adults (30 years and older), the Handan Eye Study (HES), in Handan, Hebei Province of Northern China, was conducted. ${ }^{18}$ In that study, 6830 Han people from 13 randomly selected villages in the Yongnian County of Handan were recruited. ${ }^{18}$ Six of the 13 villages where all people aged $\geq 30$ years had participated in the HES were selected for the HOMS. A total of 1238 children from the six villages, along with at least one of their parents who participated in the HES, were eligible for the HOMS. Between March 2010 and June 2010,878 of the $1238(70.9 \%)$ children were recruited into the current study. ${ }^{19}$ All children received comprehensive vision examinations and a detailed vision-related questionnaire. For parents who did not participate in the HES, the vision examinations were performed during the HOMS.

Children who underwent cycloplegic refraction and both parents who underwent noncycloplegic refraction were included in the present study. The exclusion criteria were (1) children or parents with amblyopia or strabismus, (2) children or parents with a history of either intraocular surgery or penetrating ocular trauma, and (3) children or parents with severe medical or ocular health problems. The study followed the tenets of the Declaration of Helsinki and was approved by the ethics committee of the Handan Eye Hospital. Parental written informed consent and the children's assent were obtained from the children's parents/guardians and the children themselves.

\section{Refractive Error}

Cycloplegia was performed in all children using two drops of 1\% cyclopentolate (Cyclogyl; Alcon, Fort Worth, TX, USA), administered 5 minutes apart, with a third drop administered after 20 minutes. Pupils were considered to be fully dilated if the diameter was larger than $6 \mathrm{~mm}$, and cycloplegia was recorded as being present and complete if the pupillary light reflex was absent. ${ }^{19}$ Cylcoplegic refraction of each eye was performed using an objective autorefractor-keratometer (KR8800; Topcon, Tokyo, Japan). The parental noncycloplegic refraction was performed using the same objective autorefractor in both HES and HOMS.

\section{Questionnaire}

The questionnaire used in the Sydney Myopia Study ${ }^{21}$ (available at http://www.cvr.org.au/sms.htm) was translated into Chinese with minor modifications. ${ }^{16,19}$ The purpose of this questionnaire was to survey the child's near work, outdoor activity, books read per week, and living environment. The average hours spent on near work activity were totaled for drawing, homework, reading, and handheld computer use. Time spent on outdoor activities was evaluated on the basis of responses to queries regarding playing outdoors, family picnics and barbeques, bicycle riding, hiking, and outdoor sports. Activity levels were graded into population quartiles of the average daily hours spent on these different activities. ${ }^{22}$

\section{Definitions}

The children's refractive error was defined as the combined average of the cycloplegic SE (sphere $+1 / 2$ cylinder) of both eyes. The parental refractive error was assumed to have undergone no or minor change within 4 years, and it was defined as the combined average noncycloplegic SE of the father and mother (four eyes). Refractive error difference was defined as the mean difference between the refractive error of both eyes of the parents and their respective children, that is, mean parental SE minus children's SE. ${ }^{16}$ Myopia and high myopia were defined as $\mathrm{SE}<-0.50 \mathrm{D}$ and $\mathrm{SE}<-5.0 \mathrm{D}$, respectively. ${ }^{11,19}$

\section{Data Analysis}

The data analysis methods were consistent with our previous report on the generational myopic shift in urban China. ${ }^{16}$ The RED of each family was calculated and then averaged in each age group. Since the number of subjects in some age subgroups (i.e., children aged 15,16 , or 17 years) was less than 20, adjacent age groups were combined to reduce the variation of further estimation. Both the median RED and the proportion of children with myopic SE higher than that of their parents as a function of the children's combined age were calculated and presented. Since there were families with more than one child, generalized estimating equations (GEEs) were used to establish fitting functions to investigate the trend of the RED and proportion of children having a myopic SE higher than mean parental SE. The binominal fitted functions with the RED (D)/proportion (percentage) of higher myopic SE as the dependent variable, and the children's original age (years) as the independent variable, were fitted. These had the largest $R^{2}$ and smallest quasi-likelihood under the independence model criterion (QIC) as compared to other comprehensive fitting functions such as linear or logarithmic functions. The generational myopic shift was defined as the estimated RED predicted by the binominal fitted function at 18 years of age, since the age of myopic stabilization in the majority of children was reported to be less than 18 years. ${ }^{23}$ Generalized estimating equations were also used to determine the association between RED and the putative risk factors assessed from the questionnaire after adjusting for the children's age and sex.

Data with either a normal or non-normal distribution were presented as the mean \pm 1 standard deviation and the median (quartiles), respectively. Statistical significance was determined using the rank-sum test (non-normal distribution). Statistical analysis was performed with Statistical Analysis System for Windows version 9.1 .3 (SAS, Inc., Cary, NC, USA). A $P$ value less than 0.05 was considered to be statistically significant.

\section{Results}

A total of 369 families (369 pairs of parents and 613 children) with completed refractive error data were enrolled. Twentytwo pairs of parents and 28 children were excluded due to having amblyopia, strabismus, or intraocular surgical history of 
Table 1. Characteristics of the Children and Their Parents

\begin{tabular}{lc}
\hline & Total \\
\hline Sex, male:female & $323: 262$ \\
Age, y, mean \pm SD & \\
Children & $10.6 \pm 2.5$ \\
Father & $36.4 \pm 4.2$ \\
Mother & $36.0 \pm 4.3$ \\
Refractive error, D, median (quartiles) & \\
Children* & $0.28(-0.40,0.75)$ \\
Father* & $-0.31(-0.88,0.00)$ \\
Mother* & $-0.38(-0.75,0.00)$ \\
Parents $\dagger$ & $-0.38(-0.78,-0.06)$ \\
Myopia, $n$ (\%) & \\
Children & $136(23.3)$ \\
Fathers & $212(36.2)$ \\
Mothers & $221(37.8)$ \\
High myopia, $n$ (\%) $\ddagger$ & \\
Children & \\
Fathers & \\
Mothers & $4(0.68)$ \\
Myopic parents, number $(\%) \ddagger$ & $9(1.54)$ \\
None & $2(0.34)$ \\
Either & \\
Both & $231(39.5)$ \\
& \\
&
\end{tabular}

${ }^{*}$ Refractive error was defined as the average spherical equivalent of both eyes.

† Refractive error was defined as the average spherical equivalent of father and mother.

‡ Myopia was defined as SE $<-0.50 \mathrm{D}$; high myopia was defined as $\mathrm{SE}<-5.0 \mathrm{D}$.

$\mathrm{SD}$, standard deviation.

a family member. Three hundred fifty-six families (356 pairs of parents and 585 children), including 323 boys (55.2\%) and 262 girls (44.8\%), were enrolled and used in the final analysis. There were 176, 134, 43, and 3 families with one, two, three, and four children, respectively. The mean ( \pm SD) age of the children was $10.6 \pm 2.5$ years (range, $6-17$ years). The mean $( \pm \mathrm{SD})$ age of the fathers and mothers was $36.4 \pm 4.2$ years and $36.0 \pm 4.3$ years, respectively. The SE [median, (quartiles)] of the children and parents was $0.28(-0.40,0.75) \mathrm{D}$ and -0.38 $(-0.78,-0.06) \mathrm{D}$, respectively (Table 1$)$. There were 136 (23.3\%), 212 (36.2\%), and 221 (37.8\%) myopic children, myopic fathers, and myopic mothers, respectively. There were 231 (39.5\%), 275 (47.0\%), and 79 (13.5\%) children with no, one, or two myopic parents, respectively (Table 1).
Children aged 6 to 13 years had a more hyperopic SE as compared to their parents $(P<0.05)$. There was no significant difference in the SE of the parents and children aged 14 to 15 years $(P=0.31)$, while in children aged 16 to 17 years, a more myopic SE was found in the children as compared to their parents $(P=0.026)$ (Table 2$)$. The RED [median, (quartiles)] was $-1.33(-1.99,-0.98) \mathrm{D}$ in the 6 - to 7 -year-old children. Only $1.6 \%(1 / 64)$ of the children aged 6 to 7 years exhibited a higher myopic SE than their parents. At the age of 14 to 15 years, the RED was $0.03(-0.84,1.18) \mathrm{D}$ and hence close to zero; that is, the children's SE approximated the average SE of their parents. Of the children aged 14 to 15 years, $52.9 \%$ (27/ $51)$ exhibited a higher myopic SE than their parents. However, by age 16 to 17 years, the RED increased to $0.81(-0.16,2.28)$ $\mathrm{D}$, and $68.4 \%(13 / 19)$ of the children had a higher myopic SE than their parents.

Table 3 shows the associations between RED and the putative risk factors. In the univariate linear analysis, children who were older, and girls who spent more time on near work activity, tended to have higher RED. However, after adjusting for the children's age and/or sex, only children who were older ( $\beta=0.23 \mathrm{D} /$ year, $P<0.0001)$ and girls $(\beta=0.24, P=0.01)$ tended to have a significantly higher RED. No significant differences were found among the different levels of parental education, near work, outdoor activity, books read per week, and living environments (Table 3 ). In urban areas, children who were older $(\beta=0.46 \mathrm{D} /$ year, $P<0.0001)$, spent less time on outdoor activity $(\beta=-0.21 \mathrm{D} /$ hours per day, $P=0.02)$, had less paternal education $(\beta=-0.26, P=0.027)$, and had less maternal education $(\beta=-0.27, P=0.033)$ tended to have a significantly higher RED, after adjusting for the children's age and sex (for variable age, only sex was adjusted).

Table 4 presents the estimated RED and the proportion of children having a higher myopic SE than the mean parental SE in both the rural and urban areas. The Figure presents the urban and rural binominal fitting curves of RED. Using the binominal fitted function, the rural children's predicted SE would be similar to their parents' at the age of 14 years, which is 3 years later than in the urban children. Furthermore, the estimated generational myopic shift in the rural children would be $1.03 \mathrm{D}(95 \%$ confidence interval, $0.74-1.62 \mathrm{D})$ at the age of 18 years, which is approximately $1 \mathrm{D}$ less than that found in urban children. Slightly less than half $(48.9 \%)$ of the children would have a higher myopic SE than their parents at the age of 14 years, and the estimated proportion would reach $84.2 \%$ at the age of 18 years.

\section{Discussion}

There were several interesting and important findings in the current study. First, the proportion of children having a higher

TABLE 2. Number and Refractive Error of the Children and Their Parents in the Different Age Groups

\begin{tabular}{|c|c|c|c|c|}
\hline \multirow[b]{2}{*}{ Children's Age, y } & \multirow[b]{2}{*}{ Number } & \multicolumn{3}{|c|}{ Refractive Error, D*, Median (Quartiles) } \\
\hline & & Children & Parents & $\boldsymbol{P}$ Value $\dagger$ \\
\hline $6-7$ & 64 & $0.84(0.51,1.25)$ & $-0.50(-0.81,-0.24)$ & $<0.001$ \\
\hline $8-9$ & 140 & $0.59(0.12,0.97)$ & $-0.38(-0.78,-0.12)$ & $<0.001$ \\
\hline $10-11$ & 178 & $0.15(-0.31,0.59)$ & $-0.39(-0.78,-0.03)$ & $<0.001$ \\
\hline $12-13$ & 133 & $0.06(-0.94,0.43)$ & $-0.34(-0.78,-0.06)$ & 0.013 \\
\hline $14-15$ & 51 & $-0.47(-1.43,0.41)$ & $-0.34(-0.78,0.03)$ & 0.31 \\
\hline $16-17$ & 19 & $-0.65(-2.56,0.22)$ & $-0.09(-0.50,0.16)$ & 0.026 \\
\hline
\end{tabular}

${ }^{*}$ Children's refractive error was defined as the average spherical equivalent of both eyes; parental refractive error was defined as the average spherical equivalent of father and mother.

$\dagger P$ value using rank-sum test. 
Table 3. Age- and Sex-Adjusted Refractive Error Difference Between Parents and Their Children and Its Association With Risk Factors Using Generalized Estimating Equations

\begin{tabular}{|c|c|c|c|c|c|c|}
\hline & \multirow[b]{2}{*}{$\boldsymbol{N}$} & \multirow[b]{2}{*}{ Mean \pm SD } & \multicolumn{2}{|c|}{ Crude } & \multicolumn{2}{|c|}{ Adjusted } \\
\hline & & & $\beta$ & $\boldsymbol{P}$ & $\beta$ & $\boldsymbol{P}$ \\
\hline \multicolumn{7}{|l|}{ Sex* } \\
\hline Male & 323 & $-0.71 \pm 1.31$ & 0.00 & Ref & 0.00 & Ref \\
\hline Female & 262 & $-0.31 \pm 1.41$ & 0.40 & $<0.001$ & 0.24 & 0.01 \\
\hline \multicolumn{7}{|l|}{ Father's education $\dagger$} \\
\hline Primary and less & 184 & $-0.52 \pm 1.20$ & 0.00 & Ref & 0.00 & Ref \\
\hline Junior middle school & 345 & $-0.54 \pm 1.39$ & -0.03 & 0.84 & -0.12 & 0.29 \\
\hline Senior middle school and above & 42 & $-0.54 \pm 1.80$ & -0.03 & 0.91 & -0.10 & 0.69 \\
\hline Trend test & & & -0.02 & 0.85 & -0.08 & 0.41 \\
\hline \multicolumn{7}{|l|}{ Near work activity } \\
\hline 1st quartile, lowest & 162 & $-0.78 \pm 1.18$ & 0.00 & Ref & 0.00 & Ref \\
\hline 2nd quartile & 138 & $-0.45 \pm 1.55$ & 0.33 & 0.04 & 0.10 & 0.49 \\
\hline 3rd quartile & 149 & $-0.42 \pm 1.17$ & 0.36 & 0.02 & -0.03 & 0.83 \\
\hline 4th quartile & 135 & $-0.45 \pm 1.55$ & 0.34 & 0.03 & 0.03 & 0.84 \\
\hline Trend test & & & 0.11 & 0.03 & -0.002 & 0.97 \\
\hline \multicolumn{7}{|l|}{ Outdoor activity } \\
\hline 1st quartile, lowest & 159 & $-0.60 \pm 1.39$ & 0.00 & Ref & 0.00 & Ref \\
\hline 2nd quartile & 139 & $-0.59 \pm 1.26$ & 0.02 & 0.92 & -0.15 & 0.23 \\
\hline 3rd quartile & 143 & $-0.33 \pm 1.46$ & 0.27 & 0.09 & 0.09 & 0.53 \\
\hline 4th quartile & 143 & $-0.61 \pm 1.35$ & -0.01 & 0.96 & -0.21 & 0.16 \\
\hline Trend test & & & 0.02 & 0.63 & -0.04 & 0.39 \\
\hline \multicolumn{7}{|l|}{ Books read per week, number } \\
\hline$\leq 2$ & 560 & $-0.55 \pm 1.36$ & 0.00 & Ref & 0.00 & Ref \\
\hline$>2$ & 24 & $-0.24 \pm 1.68$ & 0.31 & 0.29 & 0.12 & 0.73 \\
\hline \multicolumn{7}{|l|}{ Continuous reading, $\min \ddagger$} \\
\hline $0-15$ & 109 & $-0.61 \pm 1.39$ & 0.00 & Ref & 0.00 & Ref \\
\hline $16-30$ & 237 & $-0.58 \pm 1.19$ & 0.03 & 0.84 & 0.04 & 0.81 \\
\hline $31-45$ & 173 & $-0.56 \pm 1.46$ & 0.05 & 0.79 & -0.11 & 0.47 \\
\hline$>45$ & 65 & $-0.16 \pm 1.66$ & 0.45 & 0.04 & 0.17 & 0.48 \\
\hline Trend test & & & 0.11 & 0.08 & 0.007 & 0.92 \\
\hline \multicolumn{7}{|c|}{ Placing face unusually close to the book while reading/writing } \\
\hline No & 533 & $-0.56 \pm 1.33$ & 0.00 & Ref & 0.00 & Ref \\
\hline Yes & 30 & $-0.32 \pm 1.96$ & 0.24 & 0.35 & 0.41 & 0.14 \\
\hline \multicolumn{7}{|l|}{ High buildings in front of the house } \\
\hline No & 503 & $-0.58 \pm 1.37$ & 0.00 & Ref & 0.00 & Ref \\
\hline Yes & 65 & $-0.25 \pm 1.45$ & 0.33 & 0.07 & 0.11 & 0.50 \\
\hline \multicolumn{7}{|l|}{ The horizon in front of the house } \\
\hline No & 385 & $-0.59 \pm 1.35$ & 0.00 & Ref & 0.00 & Ref \\
\hline Yes & 160 & $-0.39 \pm 1.46$ & 0.20 & 0.13 & 0.06 & 0.64 \\
\hline
\end{tabular}

myopic SE than their parents increased as the children's age increased, similar to findings in an urban area. ${ }^{16}$ Second, with an estimation model similar to that used in an urban study, ${ }^{16}$ at the age of 14 years, the SE of the rural children was predicted to be similar to that of their parents. Furthermore, the estimated rural generational myopic shift would be $1.03 \mathrm{D}$. In our previous urban study, the predicted similarity in SE between the children and their parents would be attained at the age of 11 years, and the estimated generational myopic shift would be 1.94 D. ${ }^{16}$ Hence, there was approximately a 3-year delay between the urban and rural children with respect to attainment of the mean parental refractive error. More importantly, the generational myopic shift was approximately $1 \mathrm{D}$ less in the rural versus the urban children (Fig.). ${ }^{16}$ Since there was greater underestimation of the generational myopic shift in the hospital-based urban study ${ }^{16}$ due to the presence of a greater myopic parental refractive error, the difference in generational myopic shift between the rural and urban area would be predicted to be even greater than $1 \mathrm{D}$. Third, it was found that older children and girls tended to have a high RED in the rural area (Table 3).

People in the same part of the country (Northern China) share extremely close genetic backgrounds, including that for myopia. Hence, the children would be predicted to inherit and 
TABLE 4. Age-Specified Estimated Refractive Error Difference Between Parents and Their Children, and the Estimated Proportion of Children with a Myopic Spherical Equivalent Higher Than Mean Parental SE, in Rural and Urban Areas

\begin{tabular}{crrrrr}
\hline & \multicolumn{2}{c}{ RED } & & \multicolumn{2}{c}{ Higher Myopic Proportion } \\
\cline { 2 - 3 } \cline { 5 - 6 } $\begin{array}{c}\text { Children's } \\
\text { Age, } \mathbf{y}\end{array}$ & $\begin{array}{c}\text { Rural } \\
\text { Area }\end{array}$ & $\begin{array}{c}\text { Urban } \\
\text { Areas }\end{array}$ & & $\begin{array}{c}\text { Rural } \\
\text { Area }\end{array}$ & $\begin{array}{c}\text { Urban } \\
\text { Areas }\end{array}$ \\
\hline 6 & -1.45 & -2.86 & & 1.4 & 0.0 \\
7 & -1.29 & -2.18 & & 5.6 & 3.0 \\
8 & -1.12 & -1.56 & & 10.4 & 17.6 \\
9 & -0.95 & -0.98 & & 15.6 & 30.7 \\
10 & -0.76 & -0.45 & & 21.3 & 42.3 \\
11 & -0.57 & 0.02 & & 27.5 & 52.2 \\
12 & -0.37 & 0.45 & & 34.1 & 60.6 \\
13 & -0.16 & 0.82 & & 41.3 & 67.5 \\
14 & 0.06 & 1.15 & & 48.9 & 72.7 \\
15 & 0.29 & 1.42 & & 57.0 & 76.5 \\
16 & 0.53 & 1.64 & & 65.6 & 78.6 \\
17 & 0.77 & 1.82 & & 74.6 & 79.2 \\
18 & 1.03 & 1.94 & & 84.2 & 78.2 \\
\hline
\end{tabular}

Data on urban areas are reported with permission from Liang et al., $2013 .{ }^{16}$ develop a refractive error similar to that of their parents if no other factors were involved. However, a different urban-rural RED was found (Fig.). This difference may be due to the presence of a greater myopic refractive error in both the parents and children in the urban as compared to the rural area. ${ }^{16}$

Several factors may have contributed to the different urbanrural RED. First, Guo et al. ${ }^{24}$ recently reported that urban region of habitation was associated with the presence of myopia and longer ocular axial length in grade 1 primary students in Beijing. Urban children are putatively exposed to more intensive near work and less outdoor activity as compared to rural children from an early age. ${ }^{24,25}$ It is also expected that the impact of near work or any other environmental risk factor for myopia would be cumulative over time. ${ }^{26}$ Hence, over several years, urban children might exhibit a higher RED as compared to their parents, such that they would attain the average parental refraction approximately 3 years earlier. Second, it should be noted that migration from a rural to an urban area was very common in the last generation, while the rural population was much more stable. Thus, some of the children living in an urban area may be exposed to more myopigenic environmental factors than their rural-origin parents. Hence, differences in environmental factors such as time spent in myopigenic activities, as well as the educational pressure difference between the two genera-

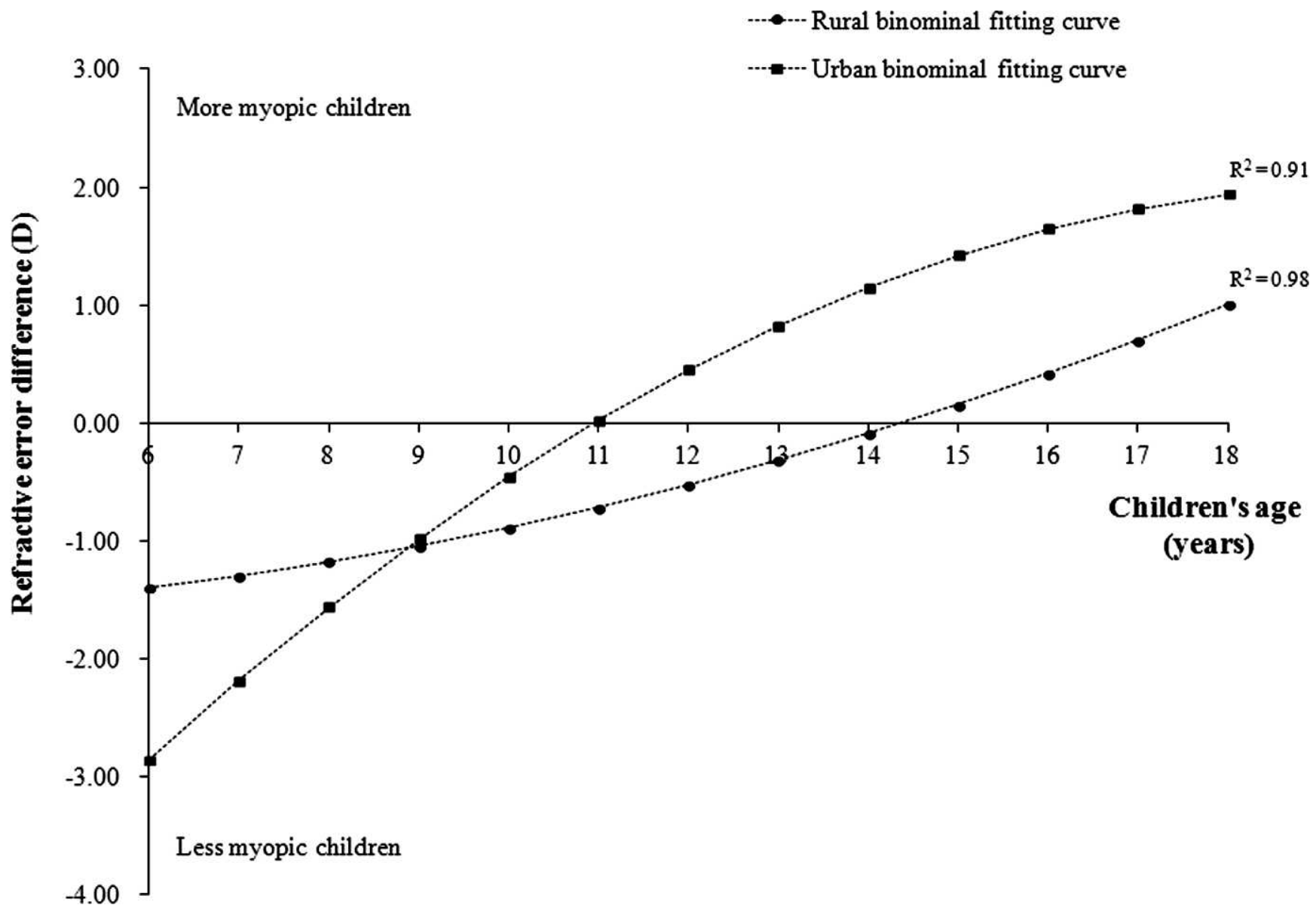

Figure. Binominal fitting curve for refractive error difference (RED) from parents to children in the rural area of China (black circles, $n=585$ ) as a function of children's' age, and the binominal fitting curve in an urban area of China from Liang et al. (black rectangles). The rural binominal fitting functions for rural children and urban children were RED $=0.0044 a^{2}+0.10 a-2.21$ and RED $=-0.025 a^{2}+1.01 a-8.00$, respectively $(a=$ children's age). RED was defined as parental spherical equivalent minus their children's spherical equivalent. The figure was reproduced with permission from Liang YB, Lin Z, Vasudevan B, et al. Generational difference of refractive error in the baseline study of the Beijing Myopia Progression Study. Br J Ophthalmol. 2013;97:765-769. 
tions at similar age/school levels (e.g., more educational pressure in primary school for children than for their parents), would be important factors in predicting the RED. This may also explain the different magnitudes of generational myopic shift between urban and rural areas.

Epidemiological studies have found a remarkable increase in the prevalence of myopia in a given area in both children ${ }^{7-9}$ and adults. ${ }^{9,27,28}$ In our previous urban study ${ }^{16}$ and in the current one in a rural area, an increase in myopic refraction from the parents to their children was found, as well as different magnitudes of generational myopic shift between the urban and rural areas. Furthermore, the final, stable myopic level would be expected to be consistent over two generations if only a physiologically based progression were presumed to exist. In the urban area, children who spent less time on outdoor activity were associated with higher RED after adjusting for their age and sex. Hence, we believe the cohort effect (i.e., increase in exposure to environmental factors) plays an important role in the myopic shift between the two generations over the last three decades. However, in the rural area, the RED was not found to be associated with environmental factors such as near work, outdoor activity, books read per week, near reading distance, or a close living environment after adjusting for the same confounders. It is noteworthy that in the rural area, the near work load was relatively low (Table 3), as most children read fewer than two books per week $(95.9 \%)$, did not read continuously for more than 45 minutes (88.9\%), and did not write with materials close to their eyes (95.2\%). In addition, outdoor activity time in the rural children (approximately 3 hours per day) was relatively longer than in the urban children (less than 2 hours per day). ${ }^{29}$ Spacious living environments, which may be associated with less myopia, ${ }^{30}$ were common in the rural area, as very few houses were close to high buildings (11.4\%). Based on these factors, we believe that the negative associations between RED and the risk factors in our cross-sectional study may be due to relatively less exposure and shorter accumulated duration for these risk factors. Further long-term explorations are required to investigate the effect of such environmental factors.

There are some possible limitations to the present study. First, there may have been an underestimation of the generational myopic shift for reasons similar to those in our urban study. ${ }^{16}$ The mean noncycloplegic SE of 16- to 45 -yearold subjects was estimated to be approximately $0.4 \mathrm{D}$ more myopic than their cycloplegic SE. ${ }^{31}$ In addition, the myopia may continue to progress after the age of 18 years in some subjects. ${ }^{32,33}$ Second, there was undersampling in some age groups. Third, only children aged 6 to 17 years were enrolled in this study. It would be optimal to include young adults older than 18 years of age as well. This would help to predict the generational myopic shift more accurately. Further studies with larger sample sizes and wider age ranges are warranted. Last, the refractive error information for the nonresponding children (approximately 30\%) was unknown.

In summary, the present study found that rural children's SE was predicted to be similar to the average SE of their parents at the age of 14 years. More importantly, the estimated generational myopic shift would be approximately $1 \mathrm{D}$ in rural China. Less generational myopic shift in rural Chinese children was found as compared to urban Chinese children. This generational difference in refraction was consistent with the increasing prevalence of myopia in the younger generation, which is likely due to changes in environmental exposure.

\section{Acknowledgments}

The authors thank Hong Jia Zhou (research assistant of The Affiliated Eye Hospital, School of Optometry and Ophthalmology,
Wenzhou Medical University) and Xiao Dong Yang and Qian Jia (Beijing Tongren Hospital, Capital Medical University) for their invaluable assistance in data collection.

Supported by the Key Technologies R\&D Program (No. 1113108019) from the Bureau of Science and Technology of Handan City, Hebei Province, China, the Beijing Science and Technology Novel Star Program (No. 2009B44), and Research Startup Project of Wenzhou Medical University (No. 89213008).

Disclosure: Z. Lin, None; T.Y. Gao, None; B. Vasudevan, None; V. Jhanji, None; K.J. Ciuffreda, None; P. Zhang, None; L. Li, None; G.Y. Mao, None; N.L. Wang, None; Y.B. Liang, None

\section{References}

1. Zhao J, Pan X, Sui R, Munoz SR, Sperduto RD, Ellwein LB. Refractive Error Study in Children: results from Shunyi District, China. Am J Ophthalmol. 2000;129:427-435.

2. He M, Zeng J, Liu Y, Xu J, Pokharel GP, Ellwein LB. Refractive error and visual impairment in urban children in southern china. Invest Ophthalmol Vis Sci. 2004;45:793-799.

3. He M, Huang W, Zheng Y, Huang L, Ellwein LB. Refractive error and visual impairment in school children in rural southern China. Ophthalmology. 2007;114:374-382.

4. Lam CS, Goldschmidt E, Edwards MH. Prevalence of myopia in local and international schools in Hong Kong. Optom Vis Sci. 2004;81:317-322.

5. Saw SM, Tong L, Chua WH, et al. Incidence and progression of myopia in Singaporean school children. Invest Ophthalmol Vis Sci. 2005;46:51-57.

6. Lim HT, Yoon JS, Hwang SS, Lee SY. Prevalence and associated sociodemographic factors of myopia in Korean children: the 2005 third Korea National Health and Nutrition Examination Survey (KNHANES III). Jpn J Ophthalmol. 2012;56:76-81.

7. Matsumura $\mathrm{H}$, Hirai $\mathrm{H}$. Prevalence of myopia and refractive changes in students from 3 to 17 years of age. Surv Ophthalmol. 1999;44(suppl 1):S109-S115.

8. Lin LL, Shih YF, Hsiao CK, Chen CJ. Prevalence of myopia in Taiwanese schoolchildren: 1983 to 2000. Ann Acad Med Singapore. 2004;33:27-33.

9. Vitale S, Sperduto RD, Ferris FL. Increased prevalence of myopia in the United States between 1971-1972 and 19992004. Arch Ophthalmol. 2009;127:1632-1639.

10. Xu L, Li J, Cui T, et al. Refractive error in urban and rural adult Chinese in Beijing. Opbthalmology. 2005;112:1676-1683.

11. Liang YB, Wong TY, Sun LP, et al. Refractive errors in a rural Chinese adult population the Handan eye study. Ophthalmology. 2009;116:2119-2127.

12. Morgan I, Rose K. How genetic is school myopia? Prog Retin Eye Res. 2005;24:1-38.

13. He M, Zheng Y, Xiang F. Prevalence of myopia in urban and rural children in mainland China. Optom Vis Sci. 2009;86:4044.

14. Morgan IG, Ohno-Matsui K, Saw SM. Myopia. Lancet. 2012; 379:1739-1748.

15. Pan CW, Ramamurthy D, Saw SM. Worldwide prevalence and risk factors for myopia. Ophthalmic Physiol Opt. 2012;32:316.

16. Liang YB, Lin Z, Vasudevan B, et al. Generational difference of refractive error in the baseline study of the Beijing Myopia Progression Study. Br J Ophthalmol. 2013;97:765-769.

17. Saw SM, Hong RZ, Zhang MZ, et al. Near-work activity and myopia in rural and urban schoolchildren in China. J Pediatr Ophthalmol Strabismus. 2001;38:149-155.

18. Liang YB, Friedman DS, Wong TY, et al. Rationale, design, methodology, and baseline data of a population-based study in 
rural China: the Handan Eye Study. Ophthalmic Epidemiol. 2009; 16:115-127.

19. Gao TY, Zhang P, Li L, et al. Rationale, design, and demographic characteristics of the Handan Offspring Myopia Study. Ophthalmic Epidemiol. 2014;21:124-132.

20. Lin Z, Vasudevan B, Liang YB, et al. Baseline characteristics of nearwork-induced transient myopia. Optom Vis Sci. 2012;89: 1725-1733.

21. Ojaimi E, Rose KA, Smith W, Morgan IG, Martin FJ, Mitchell P. Methods for a population-based study of myopia and other eye conditions in school children: the Sydney Myopia Study. Ophthalmic Epidemiol. 2005;12:59-69.

22. Rose KA, Morgan IG, Ip J, et al. Outdoor activity reduces the prevalence of myopia in children. Ophthalmology. 2008;115: 1279-1285.

23. Thorn F, Gwiazda J, Held R. Myopia progression is specified by a double exponential growth function. Optom Vis Sci. 2005; 82:286-297.

24. Guo Y, Liu LJ, Xu L, et al. Outdoor activity and myopia among primary students in rural and urban regions of Beijing. Ophthalmology. 2013;120:277-283.

25. Rose KA, Morgan IG, Smith W, Burlutsky G, Mitchell P, Saw SM. Myopia, lifestyle, and schooling in students of Chinese ethnicity in Singapore and Sydney. Arch Ophthalmol. 2008; 126:527-530.
26. Ong E, Ciuffreda KJ. Accommodation, Nearwork, and Myopia. Santa Ana, CA: Optometric Extension Program Foundation Press; 1997.

27. Seet B, Wong TY, Tan DT, et al. Myopia in Singapore: taking a public health approach. Br J Ophthalmol. 2001;85:521-526.

28. Bar Dayan Y, Levin A, Morad Y, et al. The changing prevalence of myopia in young adults: a 13-year series of population-based prevalence surveys. Invest Ophthalmol Vis Sci. 2005;46:27602765.

29. Lin Z, Vasudevan B, Jhanji V, et al. Near work, outdoor activity, and their association with refractive error. Optom Vis Sci. 2014;91:376-382.

30. Ip JM, Rose KA, Morgan IG, Burlutsky G, Mitchell P. Myopia and the urban environment: findings in a sample of 12-year-old Australian school children. Invest Ophthalmol Vis Sci. 2008; 49:3858-3863.

31. Fotouhi A, Morgan IG, Iribarren R, Khabazkhoob M, Hashemi $\mathrm{H}$. Validity of noncycloplegic refraction in the assessment of refractive errors: the Tehran Eye Study. Acta Ophthalmol. 2012;90:380-386.

32. Ellingsen KL, Nizam A, Ellingsen BA, Lynn MJ. Age-related refractive shifts in simple myopia. J Refract Surg. 1997;13: 223-228.

33. Hashemi H, Fotouhi A, Mohammad K. The age- and genderspecific prevalences of refractive errors in Tehran: the Tehran Eye Study. Ophthalmic Epidemiol. 2004;11:213-225. 